\title{
ONE IN FOUR PATIENTS WITH ADEQUATELY TREATED PRIMARY HYPOTHYROIDISM CONTINUE TO BE SYMPTOMATIC AND PERSISTING SYMPTOMS RELATED TO ONGOING THYROID AUTOIMMUNITY
}

\section{Ivy Sebastián, Jubbin Jagan Jacob, and Mary John}

Endocrine and Diabetes Unit, Department of Medicine, Christian Medical College and Hospital, Ludhiana -141008, India

\section{BACKGROUND \& OBJECTIVES}

\section{Background}

A significant percentage of patients with adequately replaced primary hypothyroidism $(\mathrm{PH})$ continue to be symptomatic. Some of these persisting symptoms maybe attributed to non restoration of neurocognitive functions and psychological well being.

\section{Objectives}

To estimate the prevalence of persisting hypothyroid symptoms in patients with primary hypothyroidism on biochemically adequate replacement therapy. To co-relate persistent symptoms with thyroid hormone levels, psychological distress scores and anti-thyroid peroxidase (TPO) antibody levels.

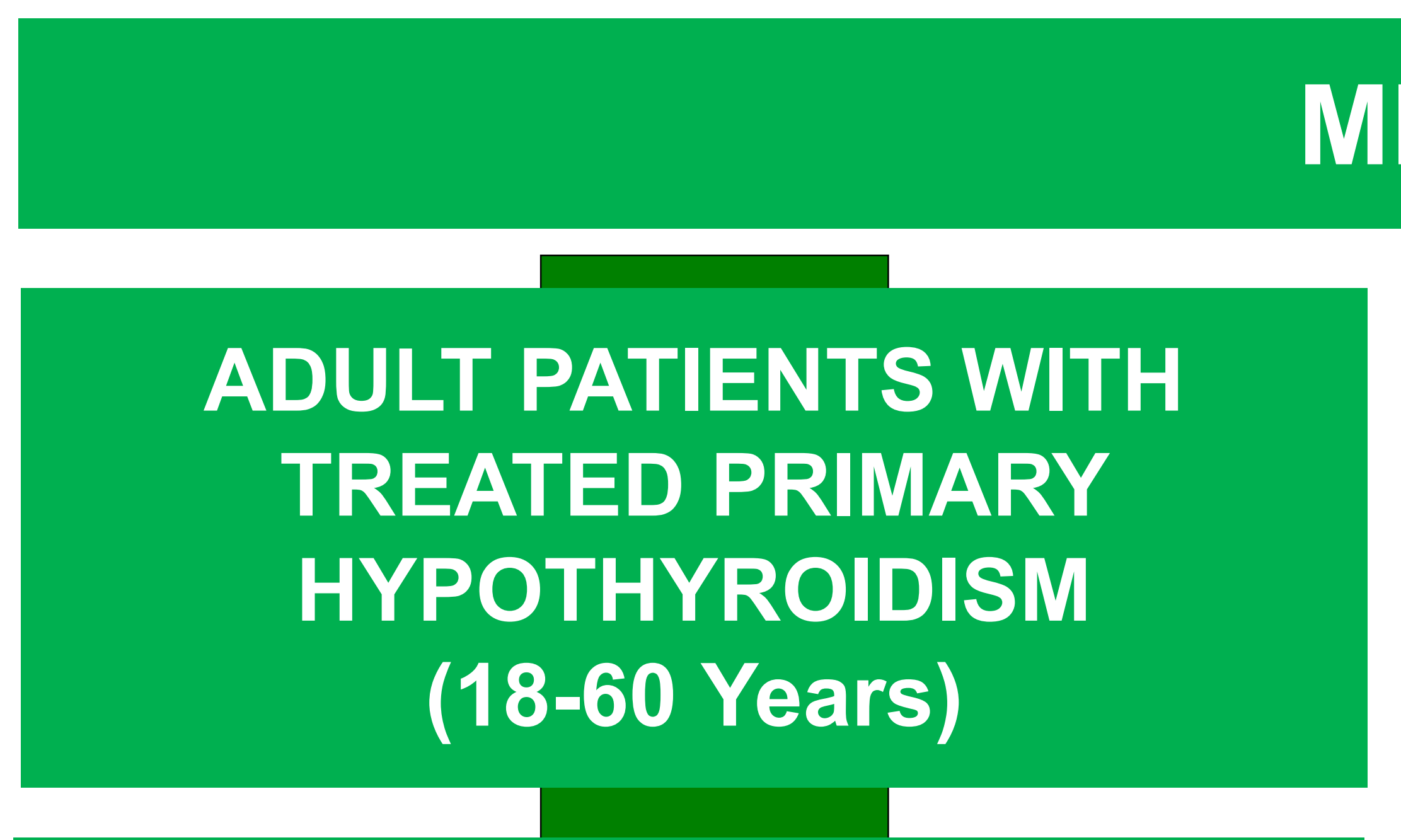

INFORMED CONSENT

TSQ, GHQ \& HAD ADMINISTERED

BIOCHEMICAL ASSESSMENTS

ANALYSIS

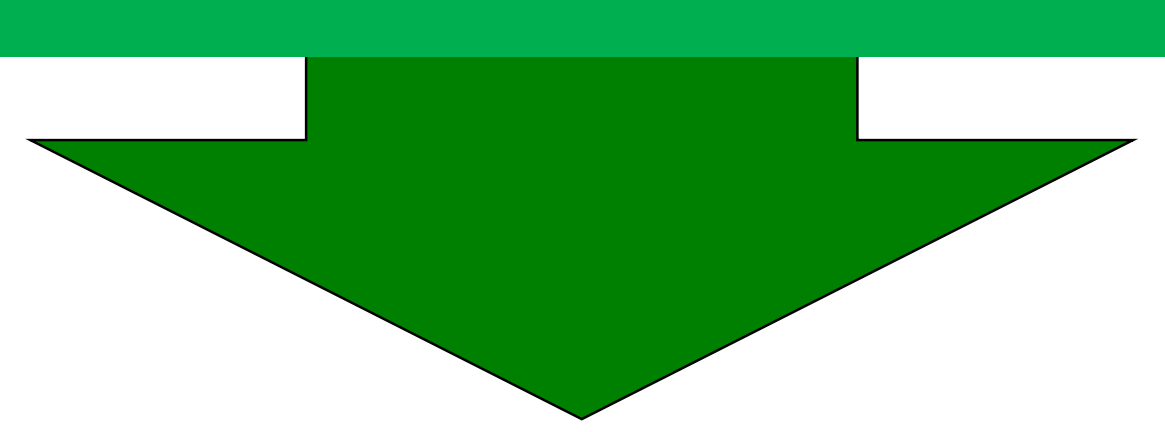

\section{METHODS}

Consequent adult patients (18 to 60 years), with $\mathrm{PH}$, on replacement therapy and having achieved biochemical euthyroidism were enrolled in the study after informed consent. They were assessed for ongoing symptoms of hypothyroidism and psychological distress using three validated questionnaires i.e. Thyroid Symptom Questionnaire (TSQ), General Health Questionnaire $(\mathrm{GHQ})^{2}$ and Hospital Anxiety and Depression (HAD) ${ }^{3}$ inventory. Serum was sampled on the same day for Free T4, Free T3, thyroid stimulating hormone (TSH) assessments and for anti-TPO antibody titres.

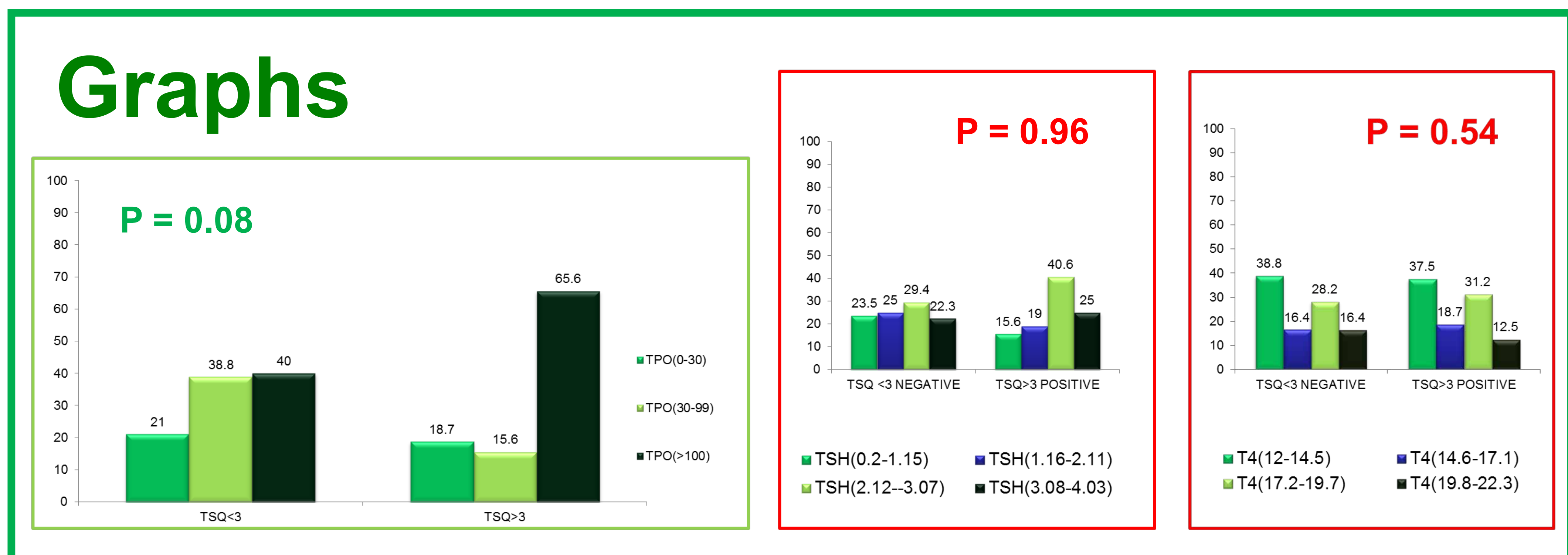

Correlation of thyroid symptoms (TSQ Scores) with ongoing auto- immunity, Free T4 and TSH levels
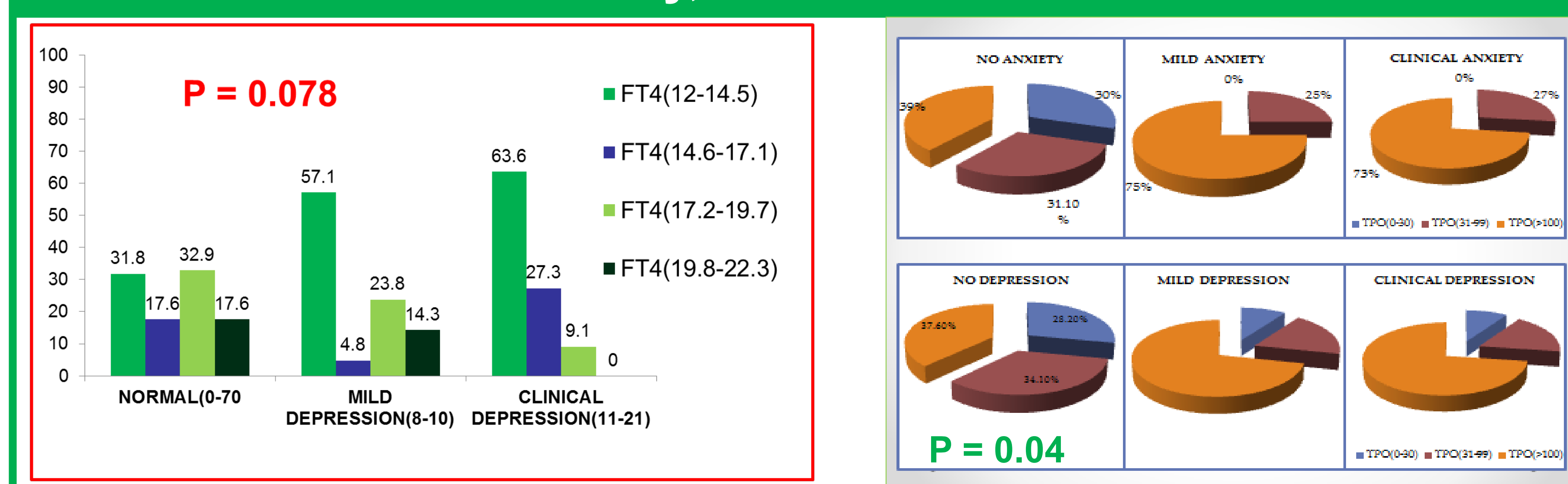

Correlation of depressive symptoms (HAD Scores) with ongoing auto- immunity, Free T4 and TSH levels

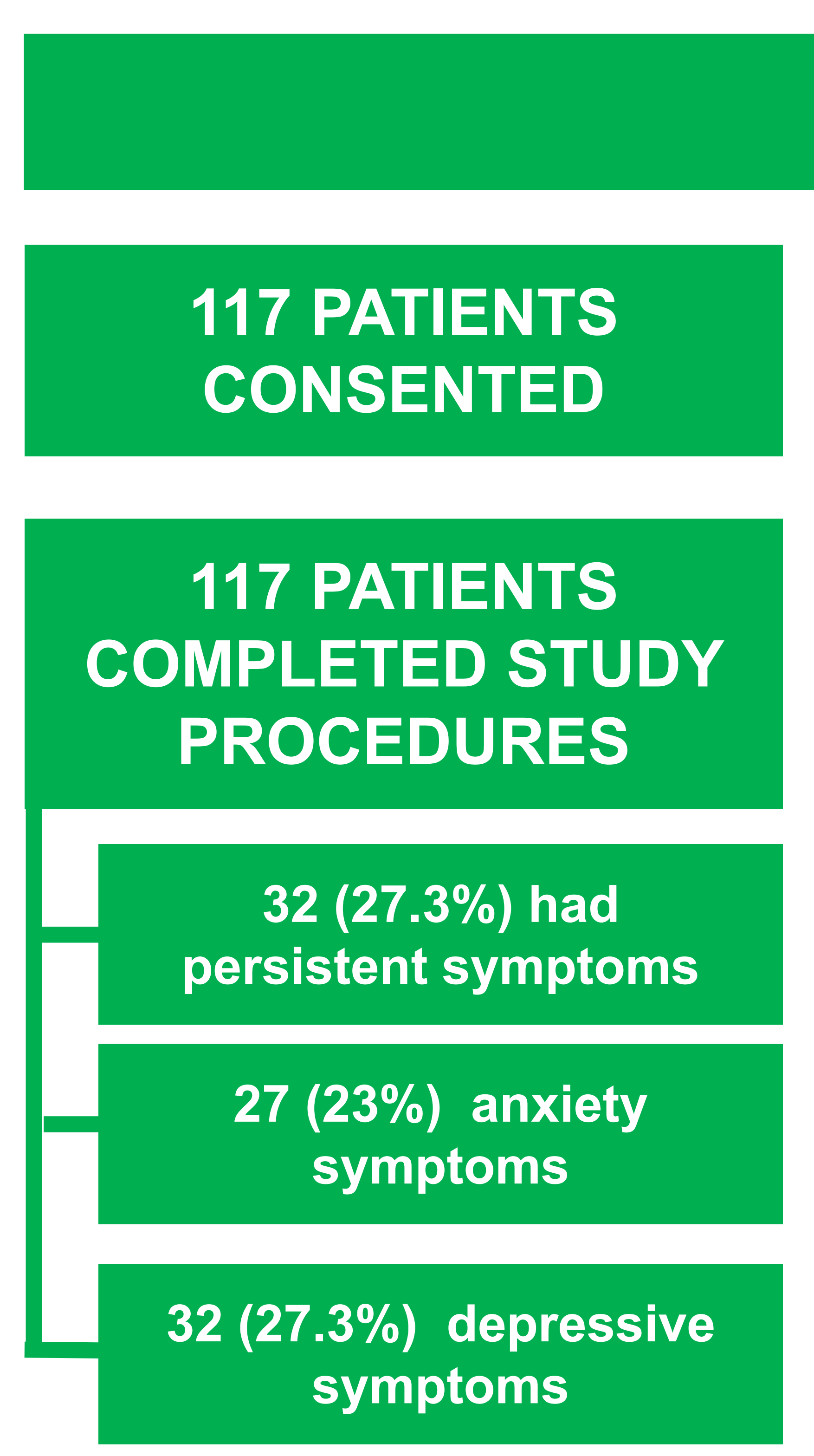

RESULTS

One hundred and seventeen patients $(F: 102, M: 15$, mean age 41 years) diagnosed with $\mathrm{PH}$ were recruited. TSQ scores revealed that $32(27.3 \%)$ patients continued to be symptomatic despite biochemical euthyroidism. FT3, FT4 and TSH levels failed to reveal any significant correlation (p0.18, p0.96, p0.54 respectively) with TSQ scores whereas TPO antibodies titres were significantly correlated with TSQ scores ( $p$ $0.008)$. HAD scores suggested that $27(23 \%)$ patients had anxiety and $32(27.3 \%)$ patients were depressed. Anti-TPO antibody titers and FT4 values had significant correlation with anxiety (p0.008 \& p0.01) while depression was correlated only with elevated antibody titres only (p0.02).

\section{$\checkmark$ OVER 25\% OF PATIENTS WITH ADEQUATELY TREATED PRIMARY HYPOTHYROIDISM CONTINUE TO BE SYMPTOMATIC}

\section{PATIENTS WITH HIGHER THYROID ANTIBODY TITRES SIGNIFYING ONGOING AUTO-IMMUNITY MORE LIKELY TO BE SYMPTOMATIC}

\section{ONGOING AUTOIMMUNITY ALSO ASSOCIATED WITH SYMPTOMS OF DEPRESSION AND ANXIETY.}

\section{References}

1. Clin Endocrinol 2002;57:577-85

2. Goldberg DP, et al. Manual of the General Health Questionnaire. Windsor, England: NFER Publishing; 1978

3. Acta Psychiatr Scand 1983: 67: 361-370. 